\title{
Treatment of Moderate-sized Kidney Stone with Third-generation Electromagnetic Shock Wave Lithotripter
}

\author{
Ivica Stojanoski ${ }^{1 \star}$, Toni Krstev ${ }^{1}$, Lazar lievski ${ }^{1}$, Nerhim Tufekgioski ${ }^{1}$, Sotir Stavridis ${ }^{2}$ \\ ${ }^{1}$ Department of Urology, General Hospital "8 ${ }^{\text {th }}$ September", Skopje, Republic of Macedonia; ${ }^{2}$ University Clinic of Urology, \\ Skopje, Republic of Macedonia
}

Edited by: Ksenija Bogoeva-Kostovska Citation: Stojanoski I, Krstev T, lievski L, Tufekgioski $\mathrm{N}$ Stavridis S. Treatment of Moderate-sized Kidney Ston with Third-generation Electromagnetic Shock Wave Lithotripter. Open Access Maced J Med Sci. 2020 Aug 30; 8(B):851-857. https://doi.org/10.3889/oamjms.2020.525 Keywords: Extracorporeal shock wave lithotripsy; Nephrolithiasis; Renal stones; Moderate-sized renal stone; Electromagnetic shock wave lithotripter "Correspondence: Ivica Stojanoski, Department of ublic of Macedonia E-mail: ivica stojanoski@gmail com Received: 26-May-2020 Revised: 20-Jun-2020 Accepted: 24-Jun-2020 opyright: ๑ 2020 Ivica Stojanoski, Toni Krstev, Lazar lievski, Nerhim Tufekgoski, Sotir Stavrid Funding: This research did not receive any financia Competing Interests: The authors have declapport competing interests exist Open Access: This is an open-access article distributed nCommercial 4.0 International License (CC BY-NC 4.0)

\begin{abstract}
BACKGROUND: The extracorporeal shock wave lithotripsy (ESWL) is a non-invasive method in the treatment of urinary tract stones and its discovery has led to a complete change in the therapeutic strategy for urolithiasis. Due to the low morbidity and excellent fragmentation of the stones, ESWL has proven to be an effective and non-invasive method in the treatment of renal stones.
\end{abstract}

AIM: The aim of this retrospective study is to evaluate the efficacy and safety of the ESWL as a monotherapy in the treatment of moderate size kidney stones with stone area (SA) of $100-300 \mathrm{~mm}^{2}$.

MATERIALS AND METHODS: We made a retrospective study of 98 patients with moderate size kidney stones with SA of $100-300 \mathrm{~mm}^{2}$, divided into two subgroups, into a group with a SA of $100-200 \mathrm{~mm}^{2}$ and with $200-300 \mathrm{~mm}^{2}$ treated with ESWL in the period of November 2018-December 2019. The patients were treated with a thirdgeneration electromagnetic lithotripter (Lithoskop ${ }^{\circledR}$, Siemens Medical Systems, Erlangen, Germany), with a source of electromagnetic shocks (Pulso ${ }^{\mathrm{TM}}$ ) and dual ultrasonographic/fluoroscopic system for detection of the stones. The stone location, size, maximum energy used, localization technique, number of shock waves, sessions, re-treatment rate, and additional procedures were reviewed. All the patients before the intervention had a complete laboratory and radiological examinations. Postoperatively, patients were monitored on the $1^{\text {st }}, 30^{\text {th }}$, and $90^{\text {th }}$ post-operative days.

RESULTS: Ninety-eight patients with solitary kidney stone with a SA of $100-300 \mathrm{~mm}^{2}$ were treated with ESWL. The study included 58 men $(59.18 \%)$ and 44 women $(40.81 \%)$. The average length and width of the stone were 15.47 $\pm 2.68 \mathrm{~mm}$ and $12.99 \pm 2.83 \mathrm{~mm}$, respectively. The average surface area of the stones in our series was $203.78 \pm$ $72.85 \mathrm{~mm}^{2}$. The mean number of treatments for the entire series of patients was $1.82 \pm 0.91$. The mean number of shock waves for the total series of patients was $3899.11 \pm 40$. The mean energy used for the overall patient series was $110106.17 \pm 21489.61 \mathrm{~mJ}$. The total re-treatment rate was $47.95 \%$. The entire rate of additional procedures was $19.38 \%$. The overall success rate (SR) in our study was $77.55 \%$. The efficiency quotient for the upper-middle and lower calyx was $55.57,57.15$, and 30.81 , respectively.

CONCLUSION: ESWL is a safe and effective method in the treatment of renal stones, and we recommend as the firs method in the treatment of moderate size kidney stone with a surface area of 100-300 $\mathrm{mm}^{2}$. The treatment of each patient should be individualized and take into account all favored and non-favored factors that influence the decision to choose extracorporeal lithotripsy as a method of treatment of medium-sized stones

\section{Introduction}

Urolithiasis is one of the most common diseases of modern society. The incidence and prevalence of renal stones are increasing as a result of changes in diet and lifestyle habits under the influence of Western countries. Nephrolithiasis is one of the most common causes of morbidity and deterioration in the quality of life, with a prevalence of $5-10 \%$. In addition, nephrolithiasis is recurrent disease and the risk of recurrence is about $50 \%$ in the first 10 years and $80 \%$ in 20 years [1]. Therefore, nephrolithiasis has a strong impact on the quality of life and socioeconomic factors.

In the era of modern medicine, urolithiasis continues to be one of the major diseases in the daily practice of urologists. An important step in the past three decades that drastically changed the approach of modern urology in the treatment of stone disease of the urinary tract (UT) was the introduction of extracorporeal shock wave lithotripsy (ESWL) for the treatment of kidney stones in 1980, when the Dornier prototype lithotripter human model 1 (or HM1), was introduced [2]. The original unmodified HM3, classified as a first-generation lithotripter, although no longer in use today, is still considered a reference standard due to its superiority and reliability [3]. To increase patient comfort and safety, second- and third-generation lithotripters were subsequently developed with various shock wave principles such as electrohydraulic, electromagnetic, and piezoelectric. Unlike HM3, where the intervention was performed in a water bath with spinal or general anesthesia, in the second-generation and third-generation lithotripters, the procedure is performed with sedoanalgesia. The introduction of modern imaging techniques in these lithotripters is 
another huge step forward in the performance of this method. The main goal of the new lithotripters is to increase the effectiveness of the breaking up of the stones, to reduce the pain during the intervention and to minimize the possibility of tissue injury. Due to the low morbidity and excellent fragmentation of the stones, ESWL has proven to be an effective and non-invasive method in the treatment of nephrolithiasis [4].

\section{Objective}

The objective of this retrospective study is to evaluate the effectiveness and safety of the ESWL as a monotherapy in the treatment of moderate size kidney stones with a stone area (SA) of $100-300 \mathrm{~mm}^{2}$, with the determination of the success rate $-\mathrm{SR}$, the re-treatment rate, need for additional procedures, the efficiency quotient (EQ), and complications after the treatment.

\section{Materials and Methods}

We made a retrospective study of 98 patients with moderate size kidney stones of 100-300 $\mathrm{mm}^{2}$, divided into two subgroups, into a group with stone size expressed as surface area (SA) of 100-200 $\mathrm{mm}^{2}$ and with 200-300 $\mathrm{mm}^{2}$, treated with ESWL using a third-generation electromagnetic lithotripter that has improved technical performance with a wide focus and deep penetration of the shock wave, in the period of November 2018-December 2019, (Lithoskop®, Siemens Medical Systems, Erlangen, Germany, with a source of electromagnetic shock waves -Pulso ${ }^{\mathrm{TM}}$, with a focal length of $160 \mathrm{~mm}$ and a beam width of up to $12 \mathrm{~mm}$; using this focal size, the focal density of the energy could be reduced, thus avoiding injury to the surrounding tissue). All the patients before the intervention had complete examinations: medical history with a physical exam, complete blood analysis (hemogram, serum values of urea, creatinine, sodium, potassium, uric acid, albumin, and proteins) urine sedimentation rate, hemostasis tests and blood group, urine culture, electrocardiogram (12 leads), X-ray image of the heart and lungs, and consultation with an anesthesiologist. The degree of anesthesia risk was determined by the scale of the American Society of Anesthesiologists.

Exclusion criteria were obesity $>100 \mathrm{~kg}$ (because of the technical limitation of the extracorporeal lithotriptor device), staghorn stones, stones smaller than $100 \mathrm{~mm}^{2}$ and stones larger than $300 \mathrm{~mm}^{2}$, untreated infection of the UT, congenital anomalies (obstruction of ureteropelvic or ureterovesical juncture), solitary kidney, presence of uncorrected coagulopathies, bilateral upper UT obstruction, patients with radiolucent stones, and pregnant women.

Before every intervention, an ultrasonographic examination of the UT and computerized tomography
(CT) urography was performed to determine the size of the stones, the anatomical characteristics of the kidney, and its function. The size of the stones was calculated based on the widest perpendicular diameters of CT urography series marked as length and width. The surface of the stones was determined by multiplying the two widest perpendicular diameters.

With patients taking aspirin or other anticoagulants, the same was discontinued 5-7 days before the treatment. All patients undertook bowel preparation with Bisacodyl (Dulcolax) $10 \mathrm{mg}$ individual oral dose and were advised to discontinue the intake of any food the night before treatment. Patients with a bacterial infection detected by urine culture were treated with antibiotic therapy and treated on after receiving sterile urine culture.

The patients were treated with a thirdgeneration electromagnetic lithotripter (Lithoskop $®$, Siemens Medical Systems, Erlangen, Germany), with a source of electromagnetic shocks (Pulso TM) and dual ultrasonographic/fluoroscopic system for detection of the stones, that has two components: An isocentric $\mathrm{C}$-arm with $\mathrm{X}$-rays to perform real-time fluoroscopy and an X-ray if needed and an inbuilt rotating ultrasound head that can be inserted in the coupling system. The entire focus length of the lithotripter is $160 \mathrm{~mm}$, the focal width at $-6 \mathrm{~dB}$ is $8-12 \mathrm{~mm}$ (depending on the set power parameters) and is in correlation with the maximum pressure of 8-75 MP. The large focus of this lithotripter allows high absolute with low-density energy doses to reduce side effects, including tissue injury.

To immobilize the patient and to reduce the movement of the stone due to respiration, we routinely used a compression belt fixed over the patient's abdomen. The patient was treated in a supine position and the X-ray and fluoroscopy were used to detect the stone. The intensity of the shock wave started from $0.1 \mathrm{~mJ}$ and gradually was increased to $4 \mathrm{~mJ}$ according to the manufacturer's recommendations. The mean and maximum energy levels during treatment automatically appeared on display after the completion of the intervention. The frequency of shock waves for the kidney stones was $90 / \mathrm{min}$, energy intensity from $0.1 \mathrm{~mJ}$ to $4 \mathrm{~mJ}$ with a maximum number of shock waves to 4000. Blood pressure (BP) was controlled alternatively every $5 \mathrm{~min}$. Continuous pulse oximetry was used for each treatment. Ureteral stents before the procedure were placed only in patients with upper UT obstruction to prevent deterioration of renal function.

A maximum of three SWL treatments was done in patients with unsuccessful complete disintegration of the stone after the first treatment. Unsuccessful fragmentation or presence of residual fragments $>4 \mathrm{~mm}$ after three treatments were considered a failed treatment and an additional alternative minimal invasion treatment was recommended to the patient. The additional measures after the treatment were defined as measures for the active removal of the stone with 
ureteroscopy or percutaneous nephrolithotomy (PCNL) when symptomatic residual fragments were present as well as any post-operative intervention after SWL. Intravenous sedoanalgesia was used in each patient using Amp Fentanyl, that is, (1 mg/kg, dose) and Amp Midazolam, that is, (0.05-0.1 $\mathrm{mg} / \mathrm{kg}$ dose). The dose was adjusted according to the reported level of pain. The patient was monitored during the procedure by checking the vital signs: Pulse heart rate, respiration rate, $\mathrm{BP}$, and oxygen saturation (pulse oximetry). On the same day, the patient was discharged from the hospital with a recommendation for oral medication for analgesia and alpha-blocker.

Postoperatively patients were monitored according to the following protocol: On the $1^{\text {st }}$ day after the procedure, a complete blood count and ultrasonography of the UT were performed, after 1-month ultrasonography of the UT and a KidneyUreter-Bladder X-ray was done and after 3 months, ultrasonography of the UT and non-contrast CT. We also evaluated the outcome by calculating the $E Q$ defined by the formula: Stone free rate $(S F R) \times 100 /$ $(100+$ rate of re-treatment in percentage + rate of additional measures in percentage).

We defined the successfulness of the treatment by determining the success rate (SR), the re-treatment rate, the need for additional procedures, the $E Q$, and complications after treatment. The treatment of patients with clinically insignificant residual fragments (CIRF) $<4 \mathrm{~mm}$ and those who were stone-free after 3 months was considered a successful treatment. Unsuccessful fragmentation or presence of residual fragments $>4 \mathrm{~mm}$ after 3 treatments were considered a failure of the treatment and an alternative minimally invasive treatment was recommended to the patient.

The effectiveness of the method was assessed by determining the absence of residual fragments of the stone or the presence of clinically insignificant fragments $<4 \mathrm{~mm}$ on the control X-ray examinations on the $1^{\text {st }}, 30^{\text {th }}$, and $90^{\text {th }}$ post-operative day. The time of the intervention was measured from the moment of the beginning of the lithotripsy until the ending of the treatment. The safety of the method was determined in relation to the frequency and severity of the complications during and after the procedure. The criterion for post-operative fever was the increase of body temperature $(\mathrm{BT})>38.5^{\circ} \mathrm{C}$ in the post-operative period without the presence of diagnostic criteria for sepsis. The complications were classified according to the modified scale of Clavien-Dindo.

\section{Statistical analysis}

Statistical for Windows 7.0 and SPSS 14.0. were used for statistical analysis in the study. The numerical variables were presented as average values and standard deviations and for the comparison of two numerical values, the Student's t-test was used if the distribution of the values was parametric or the MannWhitney $U$ test if the distribution of values was nonparametric. For the attributive variables, proportions were used. For the comparison of two attributive variables $\mathrm{X}^{2}$ test and Fisher's exact $\mathrm{p}$-test to determine the level of significance were used. For the correlation of two numerical variables, the Spearman's Rank test for correlation was used. $p<0.05$ was considered statistically significant.

\section{Results}

Ninety-eight patients with solitary kidney stone with a surface area of $100-300 \mathrm{~mm}^{2}$ were treated with ESWL. In 51 patients (52.04\%), the stone was $100-200 \mathrm{~mm}^{2}$ in size, and in 47 patients $(47.95 \%)$, the stone was $200-300 \mathrm{~mm}^{2}$ in size. The study included 58 men $(59.18 \%)$ and 44 women $(40.81 \%)$. The mean age of patients in this series was $48.79 \pm 10.25$ years. In $54(55.10 \%)$ patients, the stone was localized in the right kidney, and in $44(44.89 \%)$ patients in the left kidney. The average length and width of the stone were $15.47 \pm$ $2.68 \mathrm{~mm}$ and $12.99 \pm 2.83 \mathrm{~mm}$, respectively. The average surface area of the stones in our series was 203.78 $\pm 72.85 \mathrm{~mm}^{2}$. The stones were localized in the upper, middle, and lower calyx in 29 (29.59\%), 37 (37.75\%), and $32(32.65 \%)$ patients, respectively. In three of the treated patients $(3.06 \%)$, there was a previous surgical intervention at the ipsilateral kidney and in $9(9.18 \%)$ a DJ probe was placed (Tables 1 and 2).

Table 1: Pre-operative characteristics of patients

\begin{tabular}{|c|c|c|c|c|}
\hline Parameters & $\begin{array}{l}\text { Upper calyx } \\
\mathrm{n}=29\end{array}$ & $\begin{array}{l}\text { Middle calyx } \\
\mathrm{n}=37\end{array}$ & $\begin{array}{l}\text { Lower calyx } \\
n=32\end{array}$ & $\begin{array}{l}\text { Total } \\
\mathrm{n}=98\end{array}$ \\
\hline \multicolumn{5}{|c|}{ Gender (number/\%) } \\
\hline Men & 17 & 21 & 20 & $58(59.18)$ \\
\hline Women & 12 & 16 & 12 & $40(40.81)$ \\
\hline \multicolumn{5}{|l|}{ Side (number $/ \%$ ) } \\
\hline Right kidney & 17 & 20 & 17 & $54(55.10)$ \\
\hline Left kidney & 12 & 17 & 15 & $44(44.89)$ \\
\hline \multicolumn{5}{|c|}{ Previous procedures (number/\%) } \\
\hline Pyelolithotomy & 2 & 1 & 0 & $3(3.06)$ \\
\hline PCNL & 0 & 0 & 0 & 0 \\
\hline DJ & 2 & 4 & 3 & $9(9.18)$ \\
\hline \multicolumn{5}{|c|}{ Pre-operative anesthesiology risk according to ASA (number/\%) } \\
\hline ASA 1 class & 17 & 12 & 5 & $34(34.69)$ \\
\hline ASA 2 class & 18 & 17 & 11 & $46(46.93)$ \\
\hline ASA 3 class & 7 & 5 & 6 & $18(18.36)$ \\
\hline
\end{tabular}

The mean number of treatments for the entire series of patients was $1.82 \pm 0.91$, while the mean Table 2: Pre-operative characteristics of the stone

\begin{tabular}{ll}
\hline Medium length of the stone $(\mathrm{mm} \pm \mathrm{SD})$ & $15.47 \pm 2.68$ \\
Medium width of the stone $(\mathrm{mm} \pm \mathrm{SD})$ & $12.99 \pm 2.83$ \\
Stone surface area $\left(\mathrm{mm}^{2} \pm \mathrm{SD}\right)$ & $203.78 \pm 72.85$ \\
Features of the stone $(\mathrm{n} / \%)$ & \\
$\quad$ Solitary stones & $98(100)$ \\
$\quad$ Multiple stones & 0 \\
Localization of the stone $(\mathrm{n} / \%)$ & $29(29.59)$ \\
$\quad$ Upper calyx & $37(37.75)$ \\
$\quad$ Middle calyx & $32(32.65)$ \\
$\quad$ Lower calyx & \\
Number of patients by stone size $\left(\mathrm{mm}^{2}\right)$ & $51(52.04)$ \\
$100-200 \mathrm{~mm}^{2}$ & $47(47.95)$ \\
$200-300 \mathrm{~mm}^{2}$ & \\
\hline
\end{tabular}

number of shock waves was $3899.11 \pm 40$. 91 Overall, a statistically significant difference in both cases was 
Table 3: Characteristics of the treatment according to location

\begin{tabular}{|c|c|c|c|c|}
\hline Parameters & Upper calix $n=29$ & Middle calix $\mathrm{n}=37$ & Lower calix $n=32$ & Total $\mathrm{n}=98$ \\
\hline Mean number of session (range) & 1.59 & 1.59 & 2.28 & $1.82(1-3)$ \\
\hline Mean number of $S W(M \pm S D)$ & 3879.10 & 3958.14 & 3849.11 & 3899.11 \\
\hline Mean energy $(\mathrm{mJ} \pm \mathrm{SD})$ & $104381.00 \pm 28334.95$ & $108305 \pm 21456.40$ & $117376.97 \pm 9802.53$ & $110106.17 \pm 21489.53$ \\
\hline Re-treatment rate \% & 37.93 & 35.13 & 71.87 & 47.95 \\
\hline Auxiliary procedure \% & 10.34 & 16.21 & 31.25 & 19.38 \\
\hline Treatment success \% & 82.4 & 86.5 & 62.6 & 77.55 \\
\hline$E Q$ & 55.57 & 57.15 & 30.81 & 46.31 \\
\hline
\end{tabular}

determined only in relation to the size $(p=0.000$ and $p=0.023$, respectively), but not in relation to the localization of the stones. The total number of treatments and the total number of shock waves required for complete clearance of the stone correlated with its maximum diameter $(p=0.000$ and $p=0.023$, respectively).

The mean energy used for the overall patient series was $110106.17 \pm 21489.61 \mathrm{~mJ}$. The mean energy used for the upper, middle, and lower caliceal stones showed a borderline statistical significance $(p=0.049)$. Regarding stone size, there was not any significant difference in the energy used $(p=0.898)$. The results showed that there was a statistically significant difference only between the upper and lower calyces in the applied energy $(p=0.04)$ (Table 3$)$.

The total re-treatment rate was $47.95 \%$. The re-treatment rate for stones between upper and lower calyces was statistically significant $(p=0.007)$, as well as regarding stone size $(p=0.002)$ (Tables 3 and 4$)$.

Table 4: Characteristics of the treatment according to stone burden

\begin{tabular}{llll}
\hline Parameters & $\begin{array}{l}10-15 \mathrm{MM} \\
\mathrm{n}=51\end{array}$ & $\begin{array}{l}16-20 \mathrm{Mm} \\
\mathrm{n}=47\end{array}$ & $\begin{array}{l}\text { Total } \\
\mathrm{n}=98\end{array}$ \\
\hline Mean number of session (range) & 1.51 & 2.15 & $1.82(1-3)$ \\
Mean number of SW (Mean \pm SD) & 3814.24 & 3991.17 & 3899.11 \\
Mean energy (mJ \pm SD) & $109839.18 \pm$ & $110395.89 \pm$ & $110106.17 \pm$ \\
& 22640.25 & 20407.95 & 21489.53 \\
Re-treatment rate \% & 31.37 & 65.95 & 47.95 \\
Auxiliary procedure \% & 9.80 & 29.78 & 19.38 \\
Treatment success \% & 88.3 & 66.0 & 77.55 \\
EQ & 62.54 & 33.71 & 46.31 \\
\hline
\end{tabular}

The entire rate of additional procedures was $19.38 \%$. A statistically significant difference was determined between the upper and lower calyx $(p=0.000)$ and also regarding stone size $(p=0.014)$. Regarding the additional procedures, in $4.1 \%$ of the patients, a DJ probe was placed, in $3.1 \%$ a ureterorenoscopy with lithotripsy of migrating stones in the distal ureter was made and $12.2 \%$ of patients were treated with percutaneous nephrolithotripsy due to SWL failure. The EQ for the upper, middle, and lower calyx was $55.57,57.15$, ad 30.81 , respectively (Tables 3 and 4).

The overall SR in our study was $77.55 \%$. SFR after 3 months of treatment was $72.4 \%$ for upper calyx, $75.7 \%$ for middle calyx, and $56.7 \%$ for lower calyx, while CRIF $<4 \mathrm{~mm}$ were found in $10.3 \%, 10.8 \%$, and $6.3 \%$ in the upper, middle, and lower calyx, respectively. SFR for stones of $100-200 \mathrm{~mm}^{2}$ was $82.4 \%$ and for stones of $200-300 \mathrm{~mm}^{2}$ was $57.2 \%$, while CIRF $<4 \mathrm{~mm}$ were found in $5.9 \%$ of the stones of $100-200 \mathrm{~mm}^{2}$, and in $12.8 \%$ of the stones of $200-300 \mathrm{~mm}^{2}$. The SR for the upper, middle, and lower calyceal stones was $82.4 \%$, $86.5 \%$, and $62.6 \%$, respectively. The SR for the stone $100-200 \mathrm{~mm}$ in size was $88.3 \%$ and for the stone $200-300 \mathrm{~mm}$ in size was $66.0 \%$.

A statistically significant difference also was established between the stone size and SR $(p=0.008)$ (Table 5).

Table 5: Success rate in relation to localization and the stone burden

\begin{tabular}{|c|c|c|c|c|c|}
\hline Parameters & SFR \% & CIRF \% & Success rate \% & Failure \% & Total \% \\
\hline \multicolumn{6}{|l|}{ Stone localization } \\
\hline Upper calix $n=29$ & 72.4 & 10.3 & 82.4 & 17.2 & 100 \\
\hline Middle calix $n=37$ & 75.7 & 10.8 & 86.5 & 13.5 & 100 \\
\hline Lower calix n=32 & 56.7 & 6.3 & 62.6 & 37.5 & 100 \\
\hline Total & 68.4 & 9.2 & 77.55 & 22.4 & 100 \\
\hline \multicolumn{6}{|l|}{ Stone burden } \\
\hline $100-200 \mathrm{~mm}^{2} \mathrm{n}=51$ & 82.4 & 5.9 & 88.3 & 11.8 & 100 \\
\hline $200-300 м^{2}{ }^{2}=47$ & 53.2 & 12.8 & 66.0 & 34.0 & 100 \\
\hline Total & 68.4 & 9.2 & 77.55 & 22.4 & 100 \\
\hline
\end{tabular}

Dysuria $7.1 \%$, UTI $1.02 \%$, elevated BT $1.02 \%$, pain with admission to the hospital $3.06 \%$, and stone path (steinstrasse) 5.1\% (Table 6).

\section{Table 6: Complications}

\begin{tabular}{lll}
\hline Type of complications & $\mathrm{n}(\%)$ & Clavien-Dindo grade \\
\hline Intraoperative & $/$ & $/$ \\
Post-operative & $7(7.10)$ & $\mathrm{I}$ \\
Dysuria & $1(1.02)$ & $\mathrm{II}$ \\
UTI & $1(1.02)$ & $\mathrm{I}$ \\
Febrility $>38.5^{\circ} \mathrm{C}$ & $3(3.06)$ & $\mathrm{I}$ \\
Pain and admission & $5(5.1)$ & $\mathrm{Illb}$ \\
Stone path (steinstrasse) & $12(21.42)$ & \\
Treatment of complications & 0 & \\
Medical therapy & $3(3.06)$ & \\
Medical therapy + JJ stent & & \\
URS & & \\
URS: Ureteroscopy. &
\end{tabular}

\section{Discussion}

The ESWL is a non-invasive method in the treatment of UT stones and its discovery has led to a complete change in the therapeutic strategy for urolithiasis. Immediately after its introduction, ESWL was a widely accepted method worldwide, and today a large percentage of upper UT stones are successfully treated with this method. As a result of this significant progress and good results evident in clinical practice in the treatment of urolithiasis, the American Urological Association and the European Association of Urology (EAU) have published guidelines for the treatment of renal stones, according to the size and location of the stones [5].

However, certain issues remain controversial, including the choice of treatment for medium-sized renal 
stones. In the EAU guide, percutaneous nephrolithotripsy is recommended as a method of choice for kidney stones larger than $20 \mathrm{~mm}$, while ESWL for kidney stones $<10 \mathrm{~mm}$. Furthermore, ESWL, retrograde intrarenal surgery, and PCNL are recommended as methods of choice in the treatment of renal calculi between 10 and $20 \mathrm{~mm}$. Which minimally invasive technique will be chosen depends on several factors such as the size, number, and location of the stones, chemical composition, degree of upper UT obstruction, associated anatomical abnormalities, patient comorbidities, adequate equipment, and operator experience [6], [7]. ESWL is a preferred method in many clinical centers due to its low invasiveness, lower complication rate, and method effectiveness. In the last two decades, the emphasis has been on the development of electromagnetic shock wave lithotripters, which are more durable, with variations in the size of the focus zone and are aimed at improving the safety and efficacy of treatment [8], [9].

In this retrospective study, we present the results of the treatment of renal stones from 100 to $300 \mathrm{~mm}^{2}$ with SWL performed using a third-generation lithotripter (Lithoskop®, Siemens Medical Systems, Erlangen, Germany) [10].

In our study, the overall SR at the end of the $3^{\text {rd }}$ month was $77.55 \%$, which is in line with the results published by Saxby et al. [11], where the total SFR is $75 \%$. The total SR for upper and middle calyces was $84.6 \%$. These results are consistent with the results of most published studies such as that of Cecen et al. which establish an SWL efficiency of $87 \%$ in the treatment of stones in the upper and middle calyces with a size of 10-20 $\mathrm{mm}$ [12].

In a review of 3278 patients where SWL treatment was performed with Lithostar lithotripter, SFR after 3 months for upper, middle, and lower calyces was $82 \%, 71 \%$, and $48 \%$, respectively [13]. Similar results were presented in the study of Graff et al. [14], with SFR of $78 \%, 76 \%$, and $58 \%$ for renal stones in the upper, middle, and lower calyces in 1003 patients. In this study, the probability for a successful outcome was lower proportionately with the increase of the size of the stones. In the study of Öbek et al. [15], the entire SFR for calculi of $1.1-2 \mathrm{~cm}$ was $70 \%, 73 \%$, and $57 \%$ for the upper, middle, and lower calyx, respectively.

The results of our research are consistent with these results. Furthermore, in our study, the likelihood of treatment success was reduced directly proportionally to the increase of the stone burden. The small differences in SR after SWL for upper and middle caliceal stones are probably due to several factors, including the use of different types of lithotripters, the operator's experience, and small differences in the mean surface area of the stones in different studies.

The localization of the stones in the lower group of calyces is an important limiting factor for the effectiveness of SWL due to the difficult elimination of fragments. Infundibulopelvic angle $<70$, infundibulum length $>5 \mathrm{~mm}$, and infundibulum width $<5 \mathrm{~mm}$ are a poor prognostic factor in SWL for lower caliceal stones.

The treatment of lower caliceal stones with SWL still remains a controversial question. According to most studies, lower caliceal stones have a lower rate of efficacy after monotherapy with SWL than the stones in the middle and upper group of calyces [16].

In a meta-analysis of 13 published studies by Lingeman et al. [17] for the treatment of lower pole stones with SWL, SFR ranged between $25 \%$ and $85 \%$. The total SFR in this analysis was $60 \%$, which is identical to ours. According to the results stratified by stone size, SFR for stones smaller than $10 \mathrm{~mm}$, from 10 to $20 \mathrm{~mm}$, and $>20 \mathrm{~mm}$ was $74 \%, 56 \%$, and $33 \%$, respectively. Netto et al. [18] reported an SFR of $79 \%$ for stones in the lower pole. SFR was $78 \%, 85 \%$, and $50 \%$ for stones of $10 \mathrm{~mm}, 11-20 \mathrm{~mm}$, and $20 \mathrm{~mm}$, respectively. Rao et al. [19] in a prospective study of 257 patients for $10-20 \mathrm{~mm}$ stones presented a $69.3 \%$ $\mathrm{SR}$ at the end of 12 weeks while You et al. [20] showed an SFR of $63.6 \%$ at the end of 12 weeks for the same size of stones. The prospective study of Anup et al. [21] included radiolucent stones with a stone size of 10-20 mm located in the lower pole. The SFR in their study after 3 months was $73.8 \%$, with a re-treatment rate of $63.4 \%$ and rate of additional procedures of $22.2 \%$.

In our study, the overall SR for lower pole stones from 100 to $300 \mathrm{~mm}^{2}$ was $62.6 \%$ after 3 months of treatment. These results are consistent with the results of several published studies such as those of Rao et al. and You et al., including the results published in the meta-analysis of Lingeman et al.

The low rate of re-treatment in patients treated with Dornier HM3 (5-14\%) can only be achieved if the procedure is performed under general or spinal anesthesia. In new lithotripsies, the procedure is performed with intravenous sedoanalgesia and the re-treatment rate ranges from $20 \%$ to $30 \%$ [22]. In the study of Bierkens et al., second-generation lithotripters have a higher re-treatment rate in comparison of the first generation lithotripters $30 \%$ compared with $10 \%$ [22] Netto et al. [18] in their study show a total re-treatment rate of $42 \%$.

The overall re-treatment rate in the entire patient series in our study with a third-generation lithotripter was $47.95 \%$, which is consistent with the results of Netto et al. [18]. The re-treatment rate was largely limited to the second treatment, with a median number of session per patient of 1.82. The higher re-treatment rate was probably due to several factors such as the treatment of patients in sedoanalgesia which limited the application of high energy shock waves due to pain, but also to the fact of early second treatment which in our series was after 3 weeks to achieve higher SFR. 
In our study, the total rate in additional procedures was $19.38 \%$, similar to the study of Kumar et al. [21], where the entire rate of additional procedures was $20.2 \%$. Of the additional procedures in $4.1 \%$ of patients, a DJ probe was placed, at $3.1 \%$, a ureterorenoscopy with lithotripsy of migrating stones in the distal ureter was performed, and $12.2 \%$ of patients were treated with percutaneous nephrolithotripsy due to SWL failure.

To compare the performance of different types of lithotripters, the concept of the quotient of efficiency (EQ) was introduced, which is a more objective parameter in the evaluation of the results because it takes into account not only SFR but also the rate of re-treatment and additional procedures in determining the efficiency of the method when using different lithotripters. However, we should keep in mind that neither the percentage of residual stones nor the degree of complications is included here, so we should always be careful in comparing different EQs [8].

We also calculated the coefficient of efficiency (EQ) per calix, which in our study of the upper-middle and -lower calyces was 55.5, 57.1, and 30.8.

Complications after SWL are usually minimal and are associated with the formation and removal of fragments, effects on the kidney and surrounding tissues, effects on renal function, and post-treatment infections. Each of these complications can be prevented by following appropriate measures such as: Recognizing the limitations and contraindications to this method, recognizing and treating accompanying comorbidities in patients, treating UT infections, personalizing treatment, and improving performance and safety in the use of SWL [23].

In our study, none of the cases had a complication of Grade IV or V according to the modified Clavien-Dindo scale. Post-operative complications were classified according to the Clavien-Dindo scale I, II, and III. The overall complication rate was $17.3 \%$ where Grade I was $11.22 \%$, Grade II was 1.02, and Grade IIIb was $5.1 \%$, which is consistent with most studies, including the study of Bas et al. [24] and Turna et al. [25]. No significant intraoperative complications were observed in this study and all procedures were performed until the end of treatment.

Most of the 12 patients had conservative drug treatment with analgesic and antipyretic therapy. In one patient, oral antibiotic therapy was included, secondgeneration cephalosporin, according to an antibiogram. Out of five patients with steinstrasse, three patients underwent surgery, ureterorenoscopy, for the breakup of the stones migrating in the distal ureter.

The retrospective character of the study and the lack of data on the chemical composition of the stones are the major limiting factors in this study.

\section{Conclusion}

Our experience with the third generation of extracorporeal electromagnetic lithotripter showed that new generations of lithotripters are safe and effective in the treatment of renal stones. The overall SR in our study was $77.5 \%$. Therefore, we recommend ESWL as the first method in the treatment of a moderate size stone of $100-300 \mathrm{~mm}^{2}$. However, the probability of a successful outcome was lower in correlation with the larger stone size. Therefore, the treatment of each patient should be individualized and all favored and non-favored factors that influence the decision to choose extracorporeal lithotripsy as a method of treatment of medium-sized stones should be taken into account.

\section{References}

1. Stamatelou KK, Francis ME, Jones CA, Nyberg LM, Curhan GC Time trends in reported prevalence of kidney stones in the United States: 1976-1994. Kidney Int. 2003;63(5):1817-23. https://doi.org/10.1046/j.1523-1755.2003.00917.x PMid:12675858

2. Chaussy C, Brendel W, Schmiedt E. Extracorporeally induced destruction of kidney stones by shock waves. Lancet. 1980;2(8207):1265-8. https://doi.org/10.1016/ s0140-6736(80)92335-1 PMid:6108446

3. Chaussy C, Schmiedt E, Jocham D, Brendel W, Forssmann B, Walther V. First clinical experience with extracorporeally induced destruction of kidney stones by shock waves. J Urol. 1982;127(3):417-20. https://doi.org/10.1016/j.juro.2016.10.104 PMid:6977650

4. Gerber R, Studer UE, Danuser $H$. Is newer always better? A comparative study of 3 lithotriptor generations. J Urol. 2005;173(6):2013-6. https://doi.org/10.1097/01. ju.0000158042.41319.c4 PMid:15879807

5. Türk C, Knoll T, Petrik A, Sarica K, Skolarikos A, Straub M, et al Guidelines on Urolithiasis. Arnhem, Netherlands: European Association of Urology; 2013. https://doi.org/10.1016/j. eururo.2015.07.041

6. Motola JA, Smith AD. Therapeutic options for the management of upper tract calculi. Urol Clin North Am. 1990;17(1):191-206. PMid:1968301

7. Fuchs GJ, Patel A. Treatment of renal calculi. In: Smith AD, Badlani GH, Bagley DH, editors. Smith's Textbook of Endourology. St Louis: Quality Medical Publishing; 1996. p. 590-621.

8. Rassweiler J, Tailly G, Chaussy C. Progress in lithotripter technology. EAU Update Series. 2005;3(1):17. https://doi. org/10.1016/j.euus.2004.11.003

9. Leistner R, Wendt-Nordahl G, Grobholz R, Michel MS, Marlinghaus $\mathrm{E}$, Köhrmann $\mathrm{KU}$, et al. A new electromagnetic shock-wave generator "SLX-F2" with user-selectable dual focus size: Ex vivo evaluation of renal injury. Urol Res. 2007;35(4):165 https://doi.org/10.1007/s00240-007-0097-1

PMid:17483935 
10. Neisius A, Wöllner J, Thomas C, Roos FC, Brenner W, Hampel C, at al. Treatment efficacy and outcomes using a third generation shockwave lithotripter. BJU Int. 2013;112(7):972-81. https://doi.org/10.1111/bju.12159 PMid:24118958

11. Saxby MF, Sorahan T Slaney P, Coppinger SW. A case-control study of percutaneous nephrolithotomy versus extracorporeal shock wave lithotripsy. Br J Urol. 1997;79(3):317-23. https://doi. org/10.1046/j.1464-410x.1997.00362.x

PMid:9117207

12. Cecen K, Karadag MA, Demir A, Bagcioglu M, Kocaaslan R, Sofikerim M. Flexible ureterorenoscopy versus extracorporeal shock wave lithotripsy for the treatment of upper/middle calyx kidney stones of $10-20 \mathrm{~mm}$ : A retrospective analysis of 174 patients. Springerplus. 2014;3(1):557. https://doi. org/10.1186/2193-1801-3-557

PMid:25332859

13. El-Damanhoury H, Scharfe T, Ruth J, Roos S, Hohenfellner R. Extracorporeal shock wave lithotripsy of urinary calculi: Experience in treatment of 3,278 patients using the Siemens Lithostar and Lithostar plus. J Urol. 1991;145(3):484. https://doi. org/10.1016/s0022-5347(17)38375-1

14. Graff J, Diederichs W, Schulze H. Long-term followup in 1,003 extracorporeal shock wave lithotripsy patients. J Urol. 1988;140(3):479. https://doi.org/10.1016/ s0022-5347(17)41696-x

PMid:3411655

15. Öbek C, Onal B, Kantay K, Kalkan M, Yalçin V, Oner A, et al. The efficacy of extracorporeal shock wave lithotripsy for isolated lower pole calculi compared with isolated middle and upper caliceal calculi. J Urol. 2001;166(6):2081. https://doi. org/10.1016/s0022-5347(05)65509-7

PMid: 11696710

16. Sahinkanat T, Ekerbicer H, Onal B, Tansu N, Resim S, Citgez S, et al. Evaluation of the effects of relationships between main spatial lower pole calyceal anatomic factors on the success of shock-wave lithotripsy in patients with lower pole kidney stones. Urology. 2008;71(5):801-5. https://doi.org/10.1016/j. urology.2007.11.052

PMid: 18279941

17. Lingeman JE, Siegel YI, Steele B, Nyhuis AW, Woods JR. Management of lower pole nephrolithiasis: A critical analysis. J Urol. 1994;151(3):663-7. https://doi.org/10.1016/ s0022-5347(17)35042-5

\section{PMid:8308977}

18. Netto NR Jr., Claro JF, Lemos GC, Cortado PL. Rena calculi in lower pole calices: What is the best method of treatment? J Urol. 1991;146(3):721. https://doi.org/10.1016/ s0022-5347(17)37905-3

\section{PMid: 1875480}

19. Rao PP, Desai RM, Sabnis RB, Patel HS, Desai MR. The relative cost-effectiveness of PCNL and ESWI, for medium sized $(<2 \mathrm{~cm})$, renal calculi in a tertiary care urological referral center. Indian J Urol. 2001;17(2):121-3.

20. You YD, Kim JM, Kim ME. Comparison of the cost and effectiveness of different medical options fortreating lower calyceal stones less than $2 \mathrm{~cm}$ : Extracorporeal shock wave lithotripsy versus percutaneou nephrolithotomy. Korean J Urol. 2006;47(7):703-7. https://doi.org/10.4111/kju.2006.47.7.703

21. Kumar A, Kumar N, Vasudeva P, Jha SK, Kumar R, Singh H. A prospective, randomized comparison of shock wave lithotripsy, retrograde intrarenal surgery and miniperc for treatment of 1 to $2 \mathrm{~cm}$ radiolucent lower calyceal renal calculi: A single center experience. J Urol. 2015;193(1):160-4. https://doi.org/10.1016/j. juro.2014.07.088 PMid:25066869

22. Bierkens AF, Hendrikx AJ, de Kort VJ, de Reyke T, Bruynen CA, Bouve ER, et al. Efficacy of second generation lithotriptors: A multicenter comparative study of 2,206 extracorporeal shock wave lithotripsy treatments with the Siemens Lithostar, Dornier HM4, wolf piezolith 2300, direx tripter X-1 and breakstone lithotriptors. J Urol. 1992;148(3):1052. https://doi. org/10.1016/s0022-5347(17)36814-3

23. Evan AP, Willis LR, Connors B, Reed G, McAteer JA, Lingeman JE. Shock wave lithotripsy-induced renal injury. Am J Kidney Dis. 1991;17(4):445. https://doi.org/10.1016/s0272-6386(12)80639-1 PMid:2008914

24. Bas O, Bakirtas H, Sener NC, Ozturk U, Tuygun C Goktug HN, et al. Comparisn of shock wave lithotripsy, flexible ureterorenoscopy and percutaneous nephrolithotripsy onmoderate size renal pelvis stones. Urolithiasis. 2014;42(2):115120. https://doi.org/10.1007/s00240-013-0615-2 PMid:24162954

25. Turna B, Ekren F, Nazli O, Akbay K, Altay B, Ozyurt C, et al. Comparative results of shockwave lithotripsy for renal calculi in upper, middle, and lower calices. J Endourol. 2007;21(9):951-6. https://doi.org/10.1089/end.2006.0275

PMid:17941767 